\title{
Symposium 2
}

\section{Fermentation of non-digestible oligosaccharides by human colonic bacteria}

\author{
BY GLENN R. GIBSON, ANNE WILLEMS, SALLY READING \\ AND M. DAVID COLLINS \\ Department of Microbiology, Institute of Food Research, Earley Gate, Reading RG6 6BZ
}

The principal substrates for colonic bacterial growth are dietary carbohydrates which have escaped digestion in the upper gastrointestinal tract. These may be starches, dietary fibres, other non-absorbable sugars, sugar alcohols and oligosaccharides. In the large intestine, saccharolytic bacteria are able to metabolize carbohydrates for increased energy and growth with short-chain fatty acids (SCFA) and a variety of other metabolites, such as the electron-sink products lactate, pyruvate, ethanol, $\mathrm{H}_{2}$ and succinate, being produced. The majority of human large intestinal micro-organisms, have a strictly anaerobic metabolism, whilst numbers of facultative anaerobes are many orders of magnitude lower than those of the obligate anaerobes. Of the culturable flora, numerically predominant anaerobes are Gram-negative rods belonging to the genus Bacteroides. Other groups which have hitherto been identified as quantitatively significant include bifidobacteria, clostridia, eubacteria, lactobacilli, Gram-positive cocci, coliforms, methanogens and dissimilatory sulphatereducing bacteria. Generally, the various components of the large intestinal microbiota may be considered as exerting either pathogenic effects or they may have potential healthpromoting values. Bifidobacteria and lactobacilli are considered to belong to the latter group. Bacteria in the colon respond largely to the available fermentable substrate, and there is currently some interest in the use of diet to specifically increase groups perceived as health promoting. Non-digestible oligosaccharides seem to have this (prebiotic) potential. In particular, those that contain fructose are well fermented by bifidobacteria such that their numbers become predominant in the faeces of volunteers fed on the oligosaccharides. Whilst dietary modification of the microflora composition is therefore possible, it remains to be determined whether such effects have any positive health attributes. New molecular-based methodologies for the improved detection of gut bacteria, including species that are non-culturable by conventional methodology, will give increased precision for understanding the effects of diet on the colonic microbiota composition.

\section{GROWTH AND ACTIVITIES OF THE MICROFLORA OF THE HUMAN GASTROINTESTINAL TRACT}

In comparison with the colon, the stomach and upper small intestine are regarded as essentially sterile environments. The presence of gastric acid ensures that the stomach provides a hostile environment for bacterial growth, with most bacteria not being able to survive an environment with a pH below 4.0 (Giannella et al. 1972). Usually, the total bacterial count is below $10^{3} / \mathrm{g}$ contents. Whilst food intake probably offers some buffering capacity that allows the passage of micro-organisms through to the small intestine, those that inhabit the human stomach for any significant period of time require specialized defence mechanisms to do so. For example, Helicobacter pylori primarily colonizes the mucosal layer that overlies the gastric epithelium (Hazell et al. 1986; Rathbone \& Heatley, 
1992). To do so, it has been hypothesized that the intense urease (EC 3.5.1.5) activity associated with this micro-organism breaks down the urea in gastric juice to result in the generation of a microenvironment containing $\mathrm{NH}_{3}$ that surrounds the bacterium and offers increased protection (Goodwin et al. 1986). Moreover, the bacterium is highly motile, with six to eight polar flagellae at the terminal end of the cell. It is thought that $H$. pylori uses its motility to invade the mucus layer of the stomach and thereafter adheres to epithelial cells (Lee \& Hazell, 1988; Marshall, 1994).

In the human small intestine, bacterial counts increase from about $10^{4}$ per ml contents to about $10^{6} / 10^{7}$ at the ileo-caecal region (Gorbach et al. 1967). The transit time of gut contents in the small bowel as well as intestinal secretions and physicochemical variables such as $\mathrm{pH}$ and Eh, all contribute towards the type of microflora that develops (Macfarlane et al. 1995). The upper small gut is dominated by facultatively anaerobic and aerotolerant bacteria such as streptococci, staphylococci and lactobacilli, with bacterial numbers showing a progressive increase both in terms of numbers and degree of anaerobiosis (Hill, 1990). Although lactobacilli and streptococci tend to predominate in the terminal regions of the small intestine, there is a relatively high proportion of bacteroides and enterobacteria.

In comparison to other regions of the gastrointestinal tract, the human large intestine is an extremely complex microbial ecosystem. Transit time slows markedly in the colon and can range from $12-70 \mathrm{~h}$ (Cummings, 1978). Moreover, $\mathrm{pH}$ is more neutral and appropriate for bacterial growth. Bacterial numbers in the human large intestine are in the region of $10^{11 / 10^{12}}$ for every gram of gut contents. A number of different bacterial groups have been described as comprising the endogenous flora of the large intestine; these include bacteroides, bifidobacteria, clostridia, eubacteria, lactobacilli, fusobacteria, ruminococci, peptococci, peptostreptococci, streptococci, coliforms, methanogens and dissimilatory sulphate-reducing bacteria (Macfarlane \& Cummings, 1991). The principal substrates for bacterial growth are dietary carbohydrates which have escaped digestion in the upper gastrointestinal tract, although there is also a contribution from proteins and amino acids, as well as endogenously produced carbohydrates and glycoproteins.

Fig. 1 gives a breakdown of available substrates for the colonic microbiota. Resistant starch is often thought of as that fraction of the total starch present in diet which is not hydrolysed by pancreatic amylases. However, this starch can be metabolized by bacterially produced enzymes. Studies in vitro with faeces have demonstrated that colonic bacteria can ferment starch to form various end products, e.g. SCFA, with butyrate being suggested as clinically significant, and gases. The major starch degraders in the colon are the bacteroides, bifidobacteria and eubacteria (Englyst \& Macfarlane, 1986).

Non-starch polysaccharides (NSP) constitute a significant proportion of the standard Western diet. Current estimates indicate that up to $18 \mathrm{~g} \mathrm{NSP} / \mathrm{d}$ may be available for fermentation (Bingham et al. 1990). NSP consists of plant-cell-wall materials such as celluloses, hemicelluloses, pectins and gums. The degree of their fermentability by colonic bacteria depends on the chemical form of NSP. For example, lignified celluloses and bran are relatively inaccessible, whilst pectins and guar gum are readily fermented (Gibson et al. 1990).

Many simple sugars such as lactose, raffinose and stachyose are able to reach the colon (Cummings \& Macfarlane, 1991). In addition some food additives and sugar alcohols, for example sorbitol and xylitol, are not digested (Calloway \& Murphy, 1968; Tadesse et al. 1980). The disaccharide lactulose which is used therapeutically, can serve as an efficient $C$ 


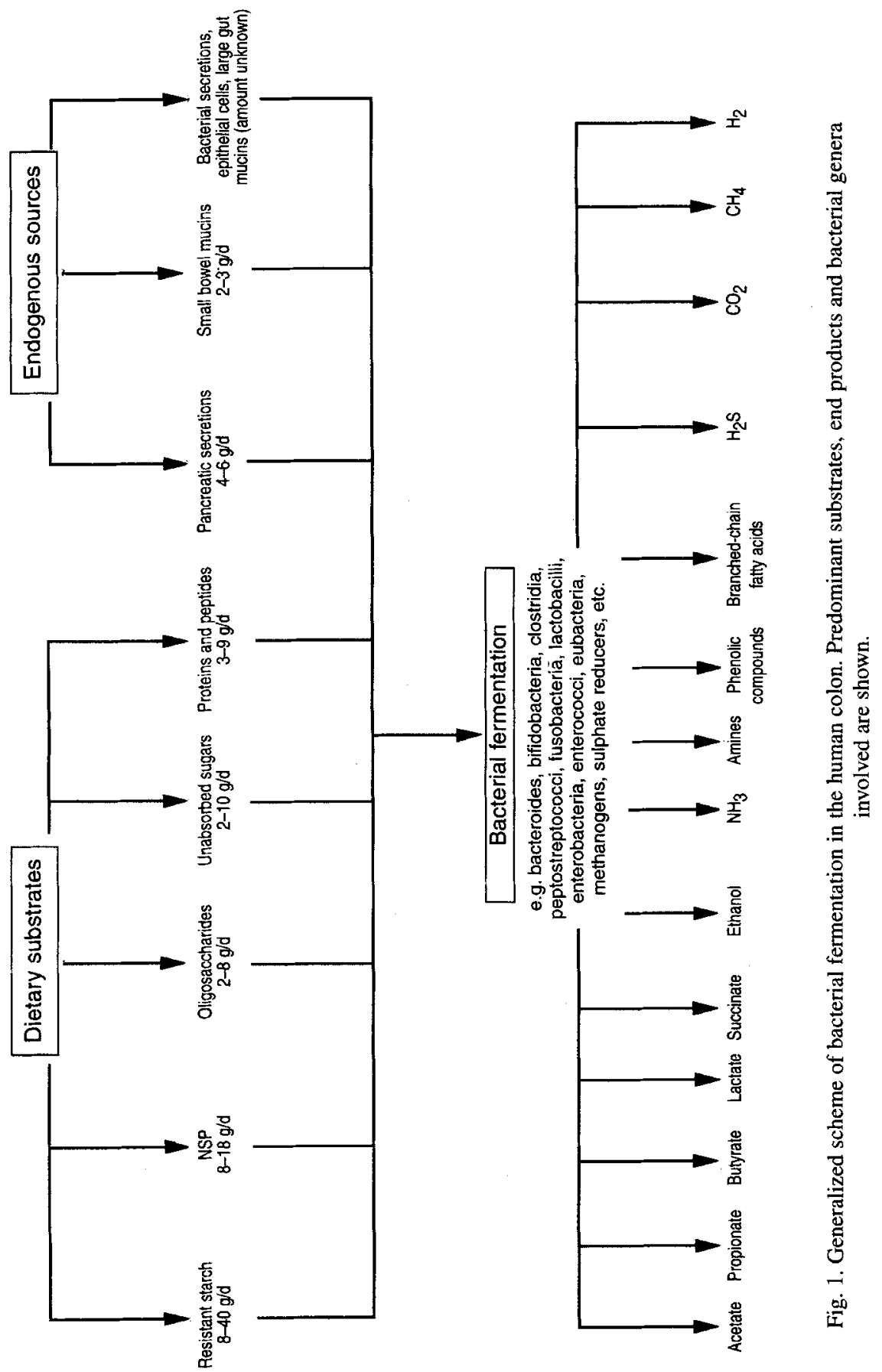


and energy source for the growth of colonic bacteria (Cummings \& Macfarlane, 1991). Currently, a range of synthetic carbohydrates are also appearing in the typical Western diet. These include methylcellulose, carboxymethylcellulose, ethylcellulose and polydextrose. Such compounds can be variably fermented (Figdor \& Bianchine, 1983; Fritz et al. 1985).

As well as growth substrates provided by the diet, the host is itself capable of producing fermentable materials. These include glycoproteins (e.g. mucins) and other polysaccharides (e.g. chondroitin sulphate). Studies from in vitro incubations have indicated that the gut microflora is able to rapidly metabolize endogenously produced substances. The important genera in this respect are thought to be bifidobacteria, clostridia, ruminococci and some bacteroides (Hoskins \& Boulding, 1981; Tsai et al. 1992; Quigley \& Kelly, 1995).

A wide variety of proteinaceous materials enter the colon and are utilized by proteolytic species of gut bacteria (Macfarlane \& Macfarlane, 1995). These include elastin, collagen and albumins as well as bacterial protein released following lysis. Pancreatic enzymes are another source of $\mathrm{N}$. Bacteroides and clostridia are among the main protease-producing genera in the colon.

The cumulative utilization of various substrates by anaerobic bacteria in the large intestine is the process of fermentation. Because of the diversity and metabolic capabilities of the microflora, gut fermentation is a complicated process. In most cases, the metabolic end products excreted by one individual species serve as a growth substrate for another. The most numerous, as well as the most versatile, polysaccharide utilizers in the colon belong to the Bacteroides genus. Other bacteria able to grow on carbohydrates are saccharolytic species belonging to genera Bifidobacterium, Ruminococcus, Eubacterium, Lactobacillus and Clostridium (Hudson \& Marsh, 1995).

The principal end products of fermentation are the SCFA acetate, propionate and butyrate (Cummings, 1981, 1995). A number of gases are also produced, which include $\mathrm{H}_{2}$, $\mathrm{H}_{2} \mathrm{~S}, \mathrm{CO}_{2}$ and $\mathrm{CH}_{4}$ (Levitt et al. 1995). Fermentation intermediates produced in the colon include ethanol, lactate, succinate and pyruvate and may be further fermented to SCFA. In addition to the major products which arise from fermentation, bacteria are also able to obtain energy for growth and the maintenance of cellular function (Fig. 1).

\section{HEALTH AND DISEASE ASPECTS OF COLONIC BACTERIOLOGY}

The end products of the colonic fermentation have varying effects on host health. SCFA may be absorbed for increased energy gain, whilst certain bacterial species may reduce gas distension problems. On the contrary, the accumulation of proteolytic end products such as $\mathrm{NH}_{3}$, amines and phenolic compounds may potentially have deleterious effects. Table 1 gives examples of how the gut microbiota and its functions may be perceived in terms of either health-promoting or harmful effects. For obvious reasons, there is some interest in modulation of the gut flora such that the former activities become dominant. This is by no means a new concept, and had its origin with the early work of Metchnikoff (1907) who advocated that the lactic microflora of the gut played an important role in disease prevention. Conversely, Metchnikoff (1907) also recognized the pathological role of certain components of the large gut. More recent years have seen an escalation in the use of probiotics both as live microbial additives to susceptible food products such as fermented milks or as preserved forms, usually freeze-dried ('over the counter').

Probiotics are defined as 'live microbial feed supplements which beneficially affect the 
Table 1. Examples of potentially pathogenic and health-promoting consequences of the large intestinal fermentation*

\begin{tabular}{|c|c|}
\hline Pathogenic or harmful effects & Health-promoting or beneficial effects \\
\hline Intestinal putrefaction & Maintenance of homeostasis \\
\hline Tissue invasion & Production of vitamins \\
\hline Potentially carcinogenic & Metabolism of procarcinogens \\
\hline Toxin production & Stimulation of immunity \\
\hline Cytotoxicity & Improved energy yield \\
\hline Diarrhoea and/or constipation & Lower gas distension \\
\hline Inflammatory bowel disease & Production of butyrate \\
\hline Site of gut infections & Inhibition of invading species \\
\hline Liver damage & Metabolism of xenobiotic compounds \\
\hline Antibiotic-associated disease & Reduction of translocation \\
\hline
\end{tabular}

* For further reading, see Rowland (1988); Gilliland (1990); Gorbach (1990); Cummings \& Macfarlane (1991); Macfarlane \& Cummings (1991); Fuller (1992); Gibson \& Roberfroid (1995); Roberfroid et al. (1995).

host animal by improving its intestinal microbial balance' (Fuller, 1989). As such, probiotics are proposed as suitable additives from both the animal and human perspectives. There is a wealth of data on the use and development of probiotics (for examples, see Fuller, 1992, 1994; Goldin \& Gorbach, 1992; Gibson, 1994; Tannock, 1995). Purported beneficial aspects that have been associated with the administration of probiotics are summarized in Table 2. Despite these claims, probiotics are viewed with some scepticism by certain areas of the scientific and medical communities. Often this is unjustified. However, poorly controlled studies, the possibility that they were not done blind and the ad hoc choice of probiotic micro-organisms have not helped. One problem is that survival of the probiotics, particularly when the colon is the target organ, may be questionable. In human subjects, because of their perceived health-promoting status, lactobacilli, bifidobacteria and streptococci/enterococci are all commonly used as probiotics. In order to target the colon, the bacteria are confronted by a number of physical and chemical barriers in the gastrointestinal tract. These include gastric acid and small intestinal secretions such as bile acids. Targeting of the large gut may not be a great problem, however, as strain selection should be carried out with appropriate resistant properties considered. In this regard Pochart et al. (1992) showed that bifidobacteria given in an oral feed could be recovered from the ileo-caecal region of the gut. Moreover, these organisms can be recovered from faeces after feeding (Bouhnik et al. 1992).

For optimum effectiveness the probiotic(s) would need to establish and become active in the large gut. However, the microbial addition is likely to be in a compromised state, because of adverse conditions higher in the gastrointestinal tract (e.g. gastric acidity, bile secretions, peristalsis). This would make its effective survival more difficult. Moreover, the bacteria would need to compete for nutrients and colonization sites with a previously wellestablished complex microbiota. It may be optimistic to expect dramatically positive results, unless the added strain has been selected, or engineered, to overcome these difficulties.

With the consideration that many potentially health-promoting bacteria, such as bifidobacteria and lactobacilli, are already resident in the human colon we have introduced 
Table 2. Purported beneficial aspects associated with probiotics*

\begin{tabular}{ll}
\hline \multicolumn{1}{c}{ Type of effect } \\
\hline Reduction of large gut carcinogenesis \\
Reduction of cholesterol levels \\
Increased lactose digestion \\
Relief from constipation \\
Stimulation of immune function \\
Enhanced phagocytosis \\
Improved bowel motility \\
Treatment and prevention of traveller's diarrhoea \\
Improved colonization resistance in infants \\
Reduction of symptoms associated with rotaviral infections \\
Modulation of the host response to infection \\
\hline \hline
\end{tabular}

* For further reading, see Gilliland \& Speck (1977); Friend et al. (1982); Gilliland \& Kim (1982); Graf (1983); Reddy et al. (1983); Gilliland et al. (1985); McGroaty et al. (1988); Conway (1989); Fuller (1989, 1992, 1994); Lin et al. (1989); Halpern et al. (1991); Huis In't Veld \& Havenaar (1991); Isolauri et al. (1991); Goldin \& Gorbach (1992); Perdigon \& Alvarez (1992); Gibson (1994); Saavedra et al. (1994); Sanders (1994); Tannock (1995); Gibson et al. (1996).

the prebiotic concept (Gibson \& Roberfroid, 1995). A prebiotic is a "non-digestible food ingredient that beneficially affects the host by selectively stimulating the growth and/or activity of one or a limited number of bacteria in the colon, that can improve the host health.' For a food ingredient to be classified as a prebiotic, it must:

(1) neither be hydrolysed, nor absorbed in the upper part of the gastrointestinal tract;

(2) be a selective substrate for one or a limited number of potentially beneficial bacteria commensal to the colon, e.g. bifidobacteria, lactobacilli, which are stimulated to grow and/or are metabolically activated;

(3) consequently, be able to alter the colonic microflora towards a healthier composition.

Any food ingredient that enters the large intestine is a candidate prebiotic. However, to be effective, selective fermentation by the colonic microbiota is required. This may occur with non-digestible complex carbohydrates, some peptides and proteins, as well as certain lipids. Because of their chemical structure, these compounds are not absorbed in the upper part of the gastrointestinal tract. However, at present, most promise has been demonstrated with non-digestible oligosaccharides.

\section{NON-DIGESTIBLE OLIGOSACCHARIDES AS PREBIOTICS}

An oligosaccharide is characterized by the number and type of its glycosyl moieties. There are usually between two and twenty monomeric units in the chain, which may be either linear or branched. The molecular weight is usually below 3500 (Roberfroid et al. 1993). Many oligosaccharides are readily soluble, have a slightly sweet taste and occur naturally in plants that form a significant part of the typical Western diet (e.g. chicory (Chicorium intybus), onion, soyabean, Jerusalem artichoke (Helianthus tuberosus), asparagus (Asparagus officinalis)). Oligosaccharides that are not hydrolysed by digestive enzymes in the upper gastrointestinal tract and, therefore, reach the colon intact, are attracting interest as prebiotics. The average Western-style diet contains below $10 \mathrm{~g}$ fructo-oligosaccharides/d 

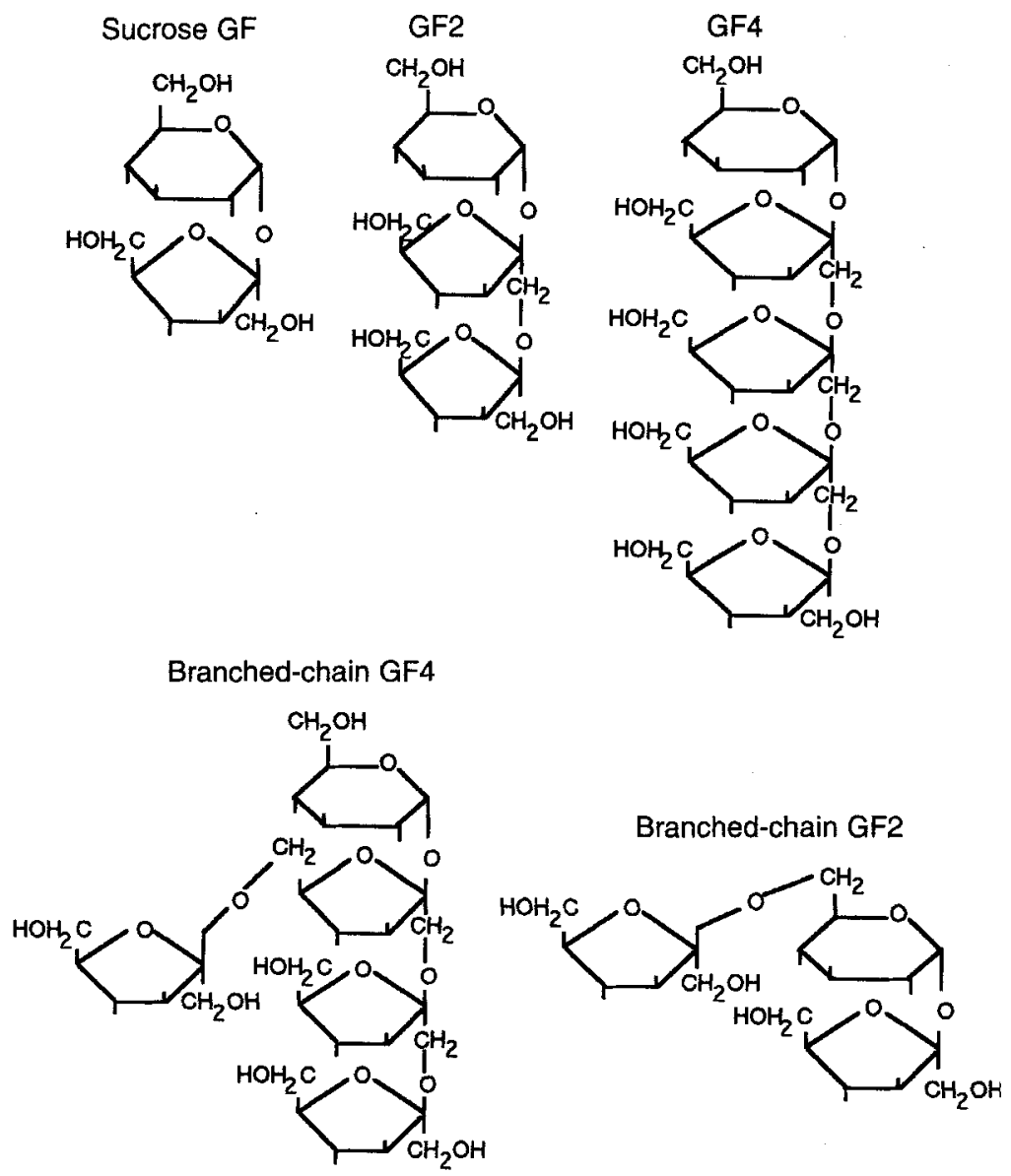

Fig. 2. Chemical structures of sucrose and various fructo-oligosaccharides. G, glucose; F, fructose.

(Van Loo et al. 1995). Non-digestible oligosaccharides include those that contain fructose, xylose, soyabean, galactose and maltose (Rumney \& Rowland, 1995; for a review of the physiological functions of mono- and oligosaccharides, see Oku, 1994).

The feeding of $50 \mathrm{~g}$ galacto-oligosaccharides/l to rats with a human-type microflora has been shown to significantly increase populations of bifidobacteria and lactobacilli, while decreasing enterobacteria (Rowland \& Tanaka, 1993), indicating their prebiotic potential. An important adjunct to this research was that certain biomarkers associated with colon cancer risk were reduced on administration of the oligosaccharides. The feeding of fructooligosaccharides in conjunction with tyrosine and tryptophan, to rats, showed a similar potential in that concentrations of $p$-cresol, a purported tumour promoter, were reduced (Hidaka et al. 1986). Preferred growth of bifidobacteria, during the fermentation of transgalactosylated oligosaccharides has been confirmed by Tanaka et al. (1983).

Oligosaccharides that contain fructose have been the subject of a recent investigation that confirms their classification as prebiotics. Chemically, fructo-oligosaccharides are short- and medium-length chains of $\beta$-D-fructans in which fructosyl units are bound by a 
$\beta$-(2-1) glycosidic linkage (Fig. 2). Their synthesis in plant cells starts by the transfer of a fructosyl moiety between two sucrose molecules (Edelman \& Dickerson, 1966), some of these molecules have a glucose unit as the initial moiety. The $\beta-(2-1)$ glycosidic bond of fructo-oligosaccharides, including the first glucose-fructose bond, is not hydrolysed by mammalian digestive enzymes (Rumessen et al. 1990). However, they are fermented by bacteria in the colon.

The fermentability of various dietary components has been compared in vitro using incubations of mixed faecal bacteria, with predominant groups in faeces enumerated using selective growth media (Wang \& Gibson, 1993). The enhanced abilities of bifidobacteria to grow on fructo-oligosaccharides in comparison with other carbohydrates was demonstrated. Generally, the other dietary carbohydrates tested exerted a more general effect on overall bacterial growth. Moreover, when bifidobacteria grew on the fructooligosaccharides, they did so at the expense of potential pathogens such as bacteroides, clostridia or coliforms, that were maintained at low levels. Such a high specificity of bifidobacteria for these oligosaccharides is likely to be due to the production of appropriate enzymes involved in their metabolism. Bifidobacteria are thought to produce relatively large amounts of $\beta$-fructosidase which is selective for $\beta-(1-2)$ glycosidic bonds present in these oligosaccharides (De Vries \& Stouthamer, 1967).

These in vitro results have been confirmed using a three-stage continuous-culture model of the large intestine (the bifidogenic effect was enhanced during conditions that stimulated the proximal colon) and selected pure cultures of gut bacteria (Gibson \& Wang, 1994a,b).

More importantly, a human volunteer trial was instigated to assess the bifidogenic effect of fructo-oligosaccharides (Gibson et al. 1995). Healthy volunteers were given a strictly controlled diet supplemented with either fructo-oligosaccharides or a placebo (sucrose). At a feeding concentration of $15 \mathrm{~g} / \mathrm{d}$, a statistically significant increase in bifidobacteria occurred, whilst bacteroides, fusobacteria and clostridia all decreased. Other bacteria tested (total aerobes, total anaerobes, lactobacilli, coliforms and Gram-positive cocci) remained more or less unchanged. A similar effect was recorded when either inulin (average degree of polymerization 10) or oligofructose (average degree of polymerization 4) was used as the test carbohydrate. Bacteroides was the numerically predominant genus on sucrose, whilst on the fructo-oligosaccharides, bifidobacteria became more predominant. A further study using $8 \mathrm{~g}$ fructo-oligosaccharides/d has given similar results (E. Menne, personal communication).

Clearly, therefore, the potential to manipulate the composition of the human colonic microbiota, through dietary prebiotics, is feasible. An unpublished study (X. Wang and G. R. Gibson, unpublished results) has shown that the addition of fructo-oligosaccharides to the uncontrolled diet of two volunteers also caused a specific increase in bifidobacteria in faeces. However, bearing in mind the types of foods that have high fructo-oligosaccharide contents (Gibson et al. 1994), it is probably not realistic to advocate increased intake to the levels required for effective flora manipulation. It is probably more feasible to add purified forms of the oligosaccharides to commonly ingested foods such as dairy products, biscuits or breakfast cereals. However, to put these data into perspective, the following research is required.

\section{Detailed and accurate analysis of the identity of gut micro-organisms}

Interesting results on the potential applications of both pro- and prebiosis have arisen. 
However, these are limited by confines of traditional gut microbiological methodologies which are invariably based on phenotypic (e.g. morphological, biochemical) properties of the organisms. Phenotypic approaches for bacterial identification are often unreliable (for example, due to poor test reproducibility, metabolic plasticity of organisms) and lack resolution. Consequently, these approaches are inadequate for the reliable qualitative and quantitative monitoring of gut microbial population fluctuations and/or variations. An additional problem is that traditional cultivation-based methods may result in underestimations of the microbiota diversity. For instance, it is now recognized that significant proportions of microbes occurring in most natural habitats (e.g. marine sediments, soil, sewage) cannot be cultivated, therefore elude isolation and are inaccessible to phenotypic identification procedures. It is likely that this problem also exists in the largegut ecosystem and, therefore, to reliably assess the efficacy of dietary intervention, for example using prebiotics, more reliable and high precision approaches are needed to monitor induced population variations. A solution to this problem lies in the application of modern high-resolution molecular-genetic techniques. In recent years microbial characterization has undergone a revolution with the advent of $16 \mathrm{~S}$ rRNA (or gene) sequence analysis (Woese, 1987). This genetic marker is currently the most powerful means for determining the interrelationships of micro-organisms and their phylogenetic characterization (including identification). In addition, the high specificity and cumulative nature of rRNA sequence data is revolutionizing the discovery and recognition of new biodiversity (Stahl, 1993). Furthermore, by utilizing nucleic acids derived directly from 'natural communities' combined with polymerase-chain reaction (cloning strategies) even non-culturable micro-organisms become accessible to characterization and/or identification (Ward et al. 1992; Amann et al. 1995; Snel et al. 1995). There is little doubt that the extent of microbial diversity within the human (and animal) gut is currently grossly underestimated. Over the next few years $16 \mathrm{~S}$ rRNA sequence analysis will greatly advance our knowledge of the true genetic diversity of the gut microbiota including organisms which evade traditional identification, due to either a lack of taxonomic resolution and/or nonculturability.

A second major benefit of rRNA sequence data is its utility in gene-probe development. rRNA gives rise to 'sequence idiosyncrasies' or 'sequence signatures'. which are characteristic of different taxa (e.g. from species to generic or suprageneric groups). Such sequences can be exploited for the design of characteristic hybridization DNA oligonucleotides and/or probes to facilitate identification at different levels within the taxonomic hierarchy (Ward et al. 1992; Amann et al. 1995). A variety of probing strategies have been developed, such as in situ microscopy-based fluorescent hybridization probing or quantitative dot blot hybridizations. These could be applied to the gut microbiota (from either 'natural' or 'model systems') and improve qualitative and quantitative population monitoring. Although such probing technologies have been extensively applied to some natural ecosystems (for a review of the literature, see Amann et al. 1995), their use in gut microbiology to date is limited (Langendijk et al. 1995). Clearly, before such techniques are routinely used in gut microbiological applications, the fidelity and efficacy of such methods need to be rigorously evaluated. There is little doubt, however, that the potential benefits of such technologies in various fields of gut microbiology (including prebiotic research) are enormous. 
Table 3. Health-promoting properties associated with bifidobacteria*

\author{
Inhibition of the growth of pathogens, either by acid formation or anti-microbial production \\ Immunomodulation \\ Reduce triacylglycerol and cholesterol levels \\ Produce vitamins, mainly of the B group \\ Reduce blood $\mathrm{NH}_{3}$ concentrations, by protonation to $\mathrm{NH}_{4}{ }^{+}$ \\ Prevent translocation \\ Restoration of the normal gut flora after anti-microbial therapy \\ Produce digestive enzymes, e.g. casein phosphatase and lysozyme (EC 3.2.1.17) \\ Reduce antibiotic-associated side effects \\ Anti-tumour properties
}

* For further reading, see Nishizawa (1960); Liescher (1961); Minagawa (1970); Kohwi et al. (1978); Mizutani \& Mitsuoka (1980); Kawase (1982); Rasic (1983); Hansen (1985); Korshunov et al. (1985); Sekine et al. (1985); Yamazaki et al. (1985); Bezkorovainy \& Miller-Catchpole (1989); Hughes \& Hoover (1991); Gibson \& Wang (1994c); Gibson et al. (1995).

\title{
The need to determine whether dietary modulation of the gut microbiota composition has a health advantage
}

The potentially positive attributes of bifidobacteria (Table 3 ) indicate that they ought to benefit health. However, cooperation between bacteriologists, clinicians, dietitians and immunologists is required. Possible areas of medical interest include systemic areas in which gut flora manipulation may be of significance, such as coronary heart disease, vitamin production and the prevention of bacterial translocation. Localized intestinal pathologies such as gastrointestinal infections, colon cancer and inflammatory disorders may be more appropriately managed using flora manipulation. In this respect, May et al. (1995) have reported that the feeding of oligosaccharides (containing fructose and xylose) to mice, suppressed the growth of a challenge from Clostridium difficile and provided protection from intestinal tissue damage. However, the most promising potential probably lies in optimal nutrition of the healthy population, and emphasizes the role that the functional food and/or nutraceutical concept has in colonic microbiology.

\section{REFERENCES}

Amann, R. I., Ludwig, W. \& Schleifer, K. H. (1995). Phylogenetic identification and in situ detection of individual microbial cells without cultivation. Microbiological Reviews 59, 143-169.

Bezkorovainy, A. \& Miller-Catchpole, R. (1989). Biochemistry and Physiology of Bifidobacteria. Boca Raton, FL: CRC Press.

Bingham, S. A., Pett, S. \& Day, K. C. (1990). NSP intake of a representative sample of British adults. Journal of Human Nutrition and Dietetics 3, 339-344.

Bouhnik, Y., Pochart, P., Marteau, P., Arlet, G., Goderel, I. \& Rambaud, J. C. (1992). Fecal recovery in humans of viable Bifidobacterium sp. ingested in fermented milk. Gastroenterology 102, 875-878.

Calloway, D. H. \& Murphy, E. L. (1968). The use of expired air to measure intestinal gas formation. Annals of the New York Academy of Sciences 150, 82-95.

Conway, P. L. (1989). Lactobacilli: Fact and fiction. In The Regulatory and Protective Role of the Normal Microflora, pp. 263-281 [R. Grubb, T. Midvedt and E. Norin, editors]. Basingstoke: Macmillan Press.

Cummings, J. H. (1978). Diet and transit through the gut. Journal of Plant Foods 3, 83-95.

Cummings, J. H. (1981). Short chain fatty acids in the human colon. Gut 22, 763-779.

Cummings, J. H. (1995). Short chain fatty acids. In Human Colonic Bacteria: Role in Nutrition, Physiology and Pathology, pp. 101-130 [G. R. Gibson and G. T. Macfarlane, editors]. Boca Raton: CRC. Press. 
Cummings, J. H. \& Macfarlane, G. T. (1991). A review: The control and consequences of bacterial fermentation in the human colon. Journal of Applied Bacteriology 70, 443-459.

De Vries, W. \& Stouthamer, A. H. (1967). Carbohydrate metabolism in Bifidobacterium bifidum var pennsylvanicus. Biochimica et Biophysica Acta 136, 415-425.

Edelman, J. \& Dickerson, A. G. (1966). The metabolism of fructose polymers in plants: transfructosylation in tubers of Helianthus tuberosus L. Biochemical Journal 98, 787-789.

Englyst, H. N. \& Macfarlane, G. T. (1986). Breakdown of resistant and readily digestible starch by human gut bacteria. Journal of the Science of Food and Agriculture 37, 699-706.

Figdor, S. K. \& Bianchine, J. R. (1983), Caloric utilization and disposition of $\left({ }^{14} \mathrm{C}\right)$ polydextrose in man. Journal of Agricultural and Food Chemistry 27, 1456-1469.

Friend, A., Farmer, R. E. \& Shahani, K. M. (1982). Effect of feeding and intraperitoneal implantation of yoghurt culture cells on Ehrlich ascites tumor. Milchwissenschaft 37, 708-710.

Fritz, M., Siebert, G. \& Kasper, H. (1985). Dose dependence of breath hydrogen and methane in healthy volunteers after ingestion of a commercial disaccharide mixture, palatinate. British Journal of Nutrition 54, 389-400.

Fuller, R. (1989). A review: Probiotics in man and animals. Joumal of Applied Bacteriology 66, 365-378.

Fuller, R. (editor) (1992). Probiotics: The Scientific Basis. London: Chapman \& Hall.

Fuller, R. (1994). Probiotics: an overview. In Human Health: The Contribution of Microorganisms, pp. 61-73 [S. A. W. Gibson, editor]. London: Springer-Verlag.

Giannella, R. A., Broitma, S. A. \& Zamcheck, N. (1972). Gastric acid barrier to ingested micro-organisms in man: studies in vivo and in vitro. Gut 13, 251-256.

Gibson, G. R., Beatty, E. B., Wang, X. \& Cummings, J. H. (1995). Selective stimulation of bifidobacteria in the human colon by oligofructose and inulin. Gastroenterology 108, 975-982.

Gibson, G. R., Macfarlane, S. \& Cummings, J. H. (1990). The fermentability of polysaccharides by mixed human faecal bacteria in relation to their suitability as bulk-forming laxatives. Letters in Applied Microbiology 11, 251-254.

Gibson, G. R. \& Roberfroid, M. B. (1995). Dietary modulation of the human colonic microbiota: Introducing the concept of prebiotics. Journal of Nutrition 125, 1401-1412.

Gibson, G. R., Saavedra, J. M., Macfarlane, S. \& Macfarlane, G. T. (1996). Probiotics and intestinal infection. In Probiotics: Therapeutic and Other Beneficial Effects [R. Fuller, editor]. London: Chapman \& Hall (In the Press).

Gibson, G. R. \& Wang, X. (1994a). Enrichment of bifidobacteria from human gut contents by oligofructose using continuous culture. FEMS Microbiology Letters 118, 121-124.

Gibson, G. R. \& Wang, X. (1994b). Bifidogenic properties of different types of fructo-oligosaccharides. Food Microbiology 11, 491-498.

Gibson, G. R. \& Wang, X. (1994c). Regulatory effects of bifidobacteria on other colonic bacteria. Journal of Applied Bacteriology 77, 412-420.

Gibson, G. R., Willis, C. L. \& Van Loo, J. V. (1994). Non-digestible oligosaccharides and bifidobacteria implications for health. International Sugar Journal 96, 381-387.

Gibson, S. A. W. (editor) (1994). Human Health: The Contribution of Microorganisms. London: SpringerVerlag.

Gilliland, S. E. (1990). Health and nutritional benefits from lactic acid bacteria. FEMS Microbiology Reviews 87, 175-188.

Gilliland, S. E. \& Kim, H. S. (1982). Effect of viable starter culture in yogurt on lactose utilization in humans. Journal of Dairy Science 67, 1-6.

Gilliland, S. E., Nelson, C. R. \& Maxwell, C. (1985). Assimilation of cholesterol by Lactobacillus acidophilus. Applied and Environmental Microbiology 49, 377-381.

Gilliland, S. E. \& Speck, M. L. (1977). Deconjugation of bile acids by intestinal lactobacilli. Applied and Environmental Microbiology 33, 15-18.

Goldin, B. R. \& Gorbach, S. L. (1992). Probiotics for humans. In Probiotics. The Scientific Basis, pp. 355-376 [R. Fuller, editor]. London: Chapman \& Hall.

Goodwin, C. S., Armstrong, J. A. \& Marshall, B. J. (1986). Campylobacter pyloridis, gastritis, and peptic ulceration. Journal of Clinical Pathology 39, 353-365.

Gorbach, S. L. (1990). Lactic acid bacteria and human health. Annual Medicine 22, 37-41.

Gorbach, S. L., Nahas, L. \& Lerner, P. I. (1967). Studies of intestinal microflora. I: Effects of diet, age and periodic sampling on numbers of faecal microorganisms in man. Gastroenterology 53, 845-855. 
Graf, W. (1983). Studies on the therapeutic properties of acidophilus milk. In Nutrition and the Intestinal Flora. Symposia of the Swedish Nutrition Foundation XV, pp. 119-121 [B. Halgren, editor]. Stockholm: Almqviste and Wiksell International.

Halpern, G. M., Vnuwing, K. G., Van der Water, J., Keen, C. L. \& Gershwin, M. E. (1991). Influence of longterm yogurt consumption in young adults. International Joumal of Immunotherapy 7, 205-210.

Hansen, R. (1985). Bifidobacteria have come to Denmark to stay. European Dairy Journal 51, $79-83$.

Hazell, S. L., Lee, A., Brady, L. \& Hennessy, W. (1986). Campylobacter pyloridis and gastritis: association with intercellular spaces and adaptation to an environment of mucus as important factors in colonization of the gastric epithelium. Journal of Infectious Diseases 153, 658-663.

Hidaka, H., Eida, T., Takiwaza, T., Tokunga, T. \& Tashiro, Y. (1986). Effects of fructooligosaccharides on intestinal flora and human health. Bifidobacteria Microflora 5, 37-50.

Hill, M. J. (1990). Factors controlling the microflora of the healthy upper gastrointestinal tract. In Human Microbial Ecology, pp. 57-85 [M. J. Hill and P. D. Marsh, editors]. Boca Raton, FL: CRC Press.

Hoskins, L. C. \& Boulding, E. T. (1981). Mucin degradation in human colonic ecosystems. Journal of Clinical Investigation 67, 163-172.

Hudson, M. J. \& Marsh, P. D. (1995). Carbohydrate metabolism in the colon. In Human Colonic Bacteria: Role in Nutrition, Physiology and Pathology, pp. 61-73 [G. R. Gibson and G. T. Macfarlane, editors]. Boca Raton, FL: CRC Press.

Hughes, D. B. \& Hoover, D. G. (1991). Bifidobacteria: Their potential for use in American dairy products. Food Technology 45, 74-83.

Huis In't Veld, J. H. J. \& Havenaar, R. (1991). Probiotics and health in man and animals. Journal of Chemistry, Technology and Biotechnology 51, 562-577.

Isolauri, E., Juntunen, M., Rautanen, T., Sillanaukee, P. \& Koivula, T. (1991). A human Lactobacillus strain (Lactobacillus casei sp. strain GG) promotes recovery from acute diarrhea in children. Pediatrics 88, 90-97.

Kawase, K. (1982). Effects of nutrients on the intestinal microflora of infants. Japanese Journal of Dairy Food Science 31, A241-A243.

Kohwi, Y., Imai, K., Tamura, Z. \& Hasimoto, Y. (1978). Antitumor effect of Bifidobacterium infantis in mice. Gann 69, 613-618.

Korshunov, U. M., Sinitsyna, N. A., Ginodman, G. A. \& Pinegin, B. V. (1985). Correction of intestinal microflora in chemotherapeutic dysbacteriosis using bifidobacterial and lactobacterial autologous strains. Microbiology Epidemiology Immunobiology 9, 20-25.

Langendijk, P. S., Scut, F., Jansen, G. J., Raangs, G. C., Kamphuis, G. R., Wilkinson, M. H. F. \& Welling, G. W. (1995). Quantitative fluorescence in situ hybridization of Bifidobacterium spp. with specific 16S rRNAtargeted probes and its application in fecal samples. Applied and Environmental Microbiology 61, 3069-3075.

Lee, A. \& Hazell, S. L. (1988). Campylobacter pylori in health and disease: an ecological perspective. Microbial Ecology in Health and Disease 1, 1-16.

Levitt, M. D., Gibson, G. R. \& Christl, S. U. (1995). In Human Colonic Bacteria: Role in Nutrition, Physiology and Pathology, pp. 131-154 [G. R. Gibson and G. T. Macfarlane, editors]. Boca Raton, FL: CRC Press.

Liescher, S. (1961). Sind die im Darm des mit Muttermilch ernährten Säuglings vorherrschenden Bifidusbakterien als nützliche Vitaminlieferanten für den Säuglingsorganismus anzusehen (Are bifidobacteria predominant in intestines of infants fed on breast milk to be regarded as useful suppliers of vitamins for the infant organism). Kinderheik 85, 265-276.

Lin, S. Y., Ayres, J. W., Winkler, W. \& Sandine, W. E. (1989). Lactobacillus effects on cholesterol: In vitro and in vivo results. Journal of Dairy Science 72, 2885-2899.

Macfarlane, G. T. \& Cummings, J. H. (1991). The colonic flora, fermentation and large bowel digestive function. In The Large Intestine: Physiology, Pathophysiology and Disease, pp. 51-92 [S. F. Phillips, J. H. Pemberton and R. G. Shorter, editors]. New York: Raven Press.

Macfarlane, G. T., Gibson, G. R., Drasar, B. S. \& Cummings, J. H. (1995). Metabolic significance of the gut microflora. In Gastrointestinal and Oesophageal Pathology, pp. 249-274 [R. Whitehead, editor]. Edinburgh: Churchill Livingstone.

Macfarlane, S. \& Macfarlane, G. T. (1995). Proteolysis and amino acid fermentation. In Human Colonic Bacteria: Role in Nutrition, Physiology and Pathology, pp. 75-100 [G. R. Gibson and G. T. Macfarlane, editors]. Boca Raton, FL: CRC Press.

McGroaty, J. A., Hawthorn, A. A. \& Reid, G. (1988). Anti-tumour activity of lactobacilli in vitro. Microbios Letters 39, 105-112. 
Marshall, B. J. (1994). Helicobacter pylori. American Journal of Gastroenterology 89, S116-\$128.

May, T., Mackie, R. I. \& Garleb, K. A. (1995). Effect of dietary oligosaccharides on intestinal growth of and tissue damage by Clostridium difficile. In Microecology and Therapy. Proceedings of the XVIII International Symposium on Microbial Ecology and Disease, pp. 158-170 [A. B. Onderdonk, P. J. Heidt and V. Rusch, editors]. Herborn-Dill: Institute for Microecology.

Metchnikoff, E. (1907). The Prolongation of Life. London: William Heinemann.

Minagawa, K. (1970). Studies on the importance of lysozyme in infants nutrition. Acta Paediatrics Japan 74, 761-767.

Mizutani, T. \& Mitsuoka, T. (1980). Inhibitory effect of some intestinal bacteria on liver tumorigenesis in gnotobiotic C3H/HE male mice. Cancer Letters 11, 89-95.

Nishizawa, Y. (1960). Physiological activity of bifidobacteria. Shonika Shinryo 23, 1213-1218.

Oku, T. (1994). Special physiological functions of newly developed mono- and oligosaccharides. In Functional Foods: Designer Foods, Pharmafoods and Nutraceuticals, pp. 202-218 [I. Goldberg, editor]. London: Chapman \& Hall.

Perdigon, G. \& Alvarez, S. (1992). Probiotics and the immune state. In Probiotics: The Scientific Basis, pp. 146-180 [R. Fuller, editor]. London: Chapman \& Hall.

Pochart, P., Mariean, P., Bouhnik, Y., Goderel, I., Bourlioux, P. \& Rambaud, J. C. (1992). Survival of bifidobacteria ingested via fermented milk during their passage through the human small intestine: an in vivo study using intestinal perfusion. American Journal of Clinical Nutrition 55, 78-80.

Quigley, M. E. \& Kelly, S. M. (1995). Structure, function, and metabolism of host mucus glycoproteins. In Human Colonic Bacteria: Role in Nutrition, Physiology and Pathology, pp. 175-199 [G. R. Gibson and G. T. Macfarlane, editors]. Boca Raton, FL: CRC Press.

Rasic, J. L. (1983). The role of dairy foods containing bifido and acidophilus bacteria in nutrition and health. European Dairy Journal 4, 80-88.

Rathbone, B. J. \& Heatley, R. V. (editors) (1992). In Helicobacter pylori and Gastroduodenal Disease. Oxford: Blackwell Scientific Publications.

Reddy, G. V., Friend, B. A., Shahani, K. M. \& Farmer, R. E. (1983). Antitumor activity of yogurt components. Journal of Food Protection 46, 8-11.

Roberfroid, M. B., Bornet, F., Bouley, C. \& Cummings, J. H. (1995). Colonic microflora: Nutrition and health. Nutrition Reviews 53, 127-130.

Roberfroid, M., Gibson, G. R. \& Dezenne, N. (1993). Biochemistry of oligofructose, a non-digestible dietary fiber: an approach to calculate its caloric value. Nutrition Reviews 51, 137-146.

Rowland, I. R. (1988). Role of the Gut Flora in Toxicity and Cancer. London: Academic Press.

Rowland, I. R. \& Tanaka, R. (1993). The effects of transgalactosylated oligosaccharides on gut flora metabolism in rats associated with human faecal microflora. Joumal of Applied Bacteriology 74, 667-674.

Rumessen, J. J., Bode, S., Hamberg, O. \& Hoyer, E. G. (1990). Fructans of Jerusalem artichokes: intestinal transport, absorption, fermentation and influence on blood glucose, insulin and C-peptide responses in healthy subjects. American Journal of Clinical Nutrition 52, 675-681.

Rumney, C. \& Rowland, I. R. (1995). Non-digestible oligosaccharides - potential anti-cancer agents? British Nutrition Foundation Nutrition Bulletin 20, 194-203.

Saavedra, J. M., Bauman, N. A., Oung, I., Perman, J. A. \& Yolken, R. H. (1994). Feeding of Bifidobacterium bifidum and Streptococcus thermophilus to infants in hospital for prevention of diarthoea and shedding of rotavirus. Lancet 344, 1046-1049.

Sanders, M. E. (1994). Lactic acid bacteria as promoters of human health. In Functional Foods: Designer Foods, Pharmafoods and Nutraceuticals, pp. 294-322 [I. Goldberg, editor]. London: Chapman \& Hall.

Sekine, K., Toida, T., Saito, M., Kuboyama, M., Kawashima, T. \& Hashimoto, Y. (1985). A new morphologically characterized cell wall preparation (whole peptidoglycan) from Bifidobacterium infantis with a higher efficacy on the regression of an established tumor in mice. Cancer Research 45, 1300-1307.

Snel, J., Heinen, P. P., Blok, H. J., Carman, R. J., Duncan, A. J., Allen, P. C. \& Collins, M. D. (1995). Comparison of 16S rRNA sequences of segmented filamentous bacteria isolated from mice, rats and chickens and proposal of 'Candidatus arthromitus'. International Journal of Systematic Bacteriology 45, 1780-1782.

Stahl, D. A. (1993). The natural history of microorganisms. ASM News 59, 609-613.

Tadesse, K., Smith, D. \& Eastwood, M. A. (1980). Breath hydrogen $\left(\mathrm{H}_{2}\right)$ and methane $\left(\mathrm{CH}_{4}\right)$ excretion patterns in normal man and in clinical patients. Quarterly Journal of Experimental Physiology 65, 85-97.

Tanaka, R., Takayama, H., Morotomi, M., Kuroshima, T., Ueyama, S., Matsumoto, K., Kuroda, A. \& Mutai, M. (1983). Effects of administration of TOS and Bifidobacterium breve 4006 on the human fecal flora. Bifidobacteria Microflora 2, 17-24. 
Tannock, G. W. (1995). The role of probiotics. In Human Colonic Bacteria: Role in Nutrition, Physiology, and Pathology, pp. 257-271 [G. R. Gibson and G. T. Macfarlane, editors]. Boca Raton, FL: CRC Press.

Tsai, H. H., Sunderland, D., Gibson, G. R., Hart, C. A. \& Rhodes, J. M. (1992). A novel mucin sulphatase from human faeces: its identification, purification and characterisation. Clinical Science 82, 447-454.

Van Loo, J., Coussement, P., De Leenheer, L., Hoebregs, H. \& Smits, G. (1995). On the presence of inulin and oligofructose as natural ingredients in the Western diet. CRC Reviews in Food Science and Technology 35, $525-552$.

Wang, X. \& Gibson, G. R. (1993). Effects of the in vitro fermentation of oligofructose and inulin by bacteria growing in the human large intestine. Journal of Applied Bacteriology 75, 373-380.

Ward, D. M., Bateson, M. M., Weller, R. \& Ruff-Roberts, A. L. (1992). Ribosomal RNA analysis of microorganisms as they occur in nature. Advances in Microbial Ecology 12, 219-286.

Woese, C. R. (1987). Bacterial evolution. Microbiological Reviews 51, 221-271.

Yamazaki, S., Machii, K., Tsuyuki, S., Momose, H., Kawashima, T. \& Ueda, K. (1985). Immunological responses to monoassociated Bifidobacterium longum and their relation to prevention of bacterial invasion. Immunology 56, 43-50. 